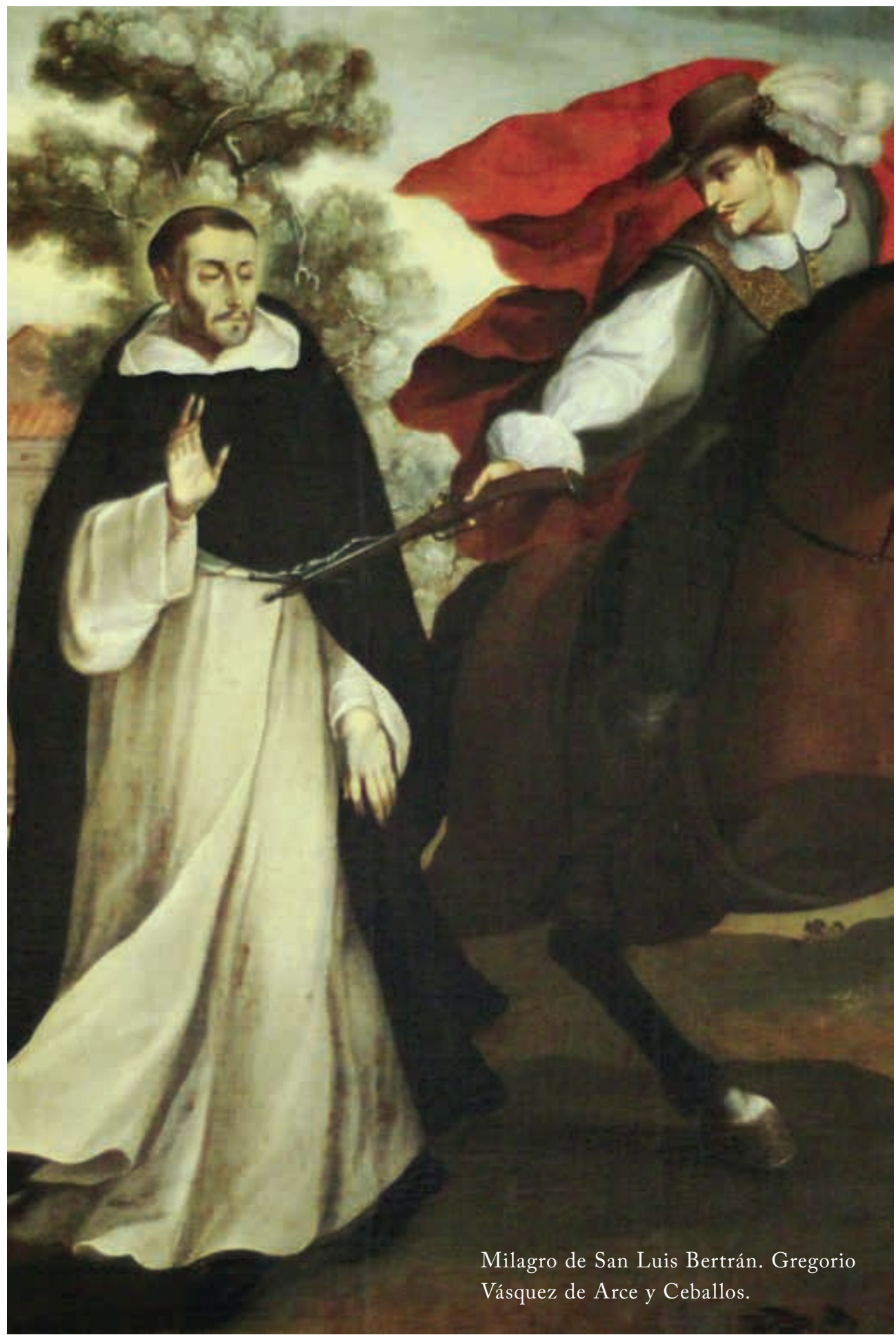




\section{Los frailes dominicos en la Nueva Granada y en la antigua provincia de Tunja}

$\mathbf{L}$

a Orden de Predicadores, autorizada por

la Corona española para evangelizar a los indígenas del Nuevo Mundo, llegó a la isla de La Española hacia el mes de septiembre de I5IO, con una primera expedición de cuatro religiosos (Rubio, I98I, pp. III-I45; Las Casas, I957, v. 96, p. I32; Medina, 1983, p. 50). La ciudad de Santo Domingo fue el puente que unió ambos continentes y permitió iniciar la evangelización de América; su primer convento muy pronto se convirtió en una escuela para la defensa de la dignidad de los pueblos indígenas. Entre finales de I5 28 e inicios de 1529 pisó tierra de la Nueva Granada el primer grupo de dominicos, cuyo 


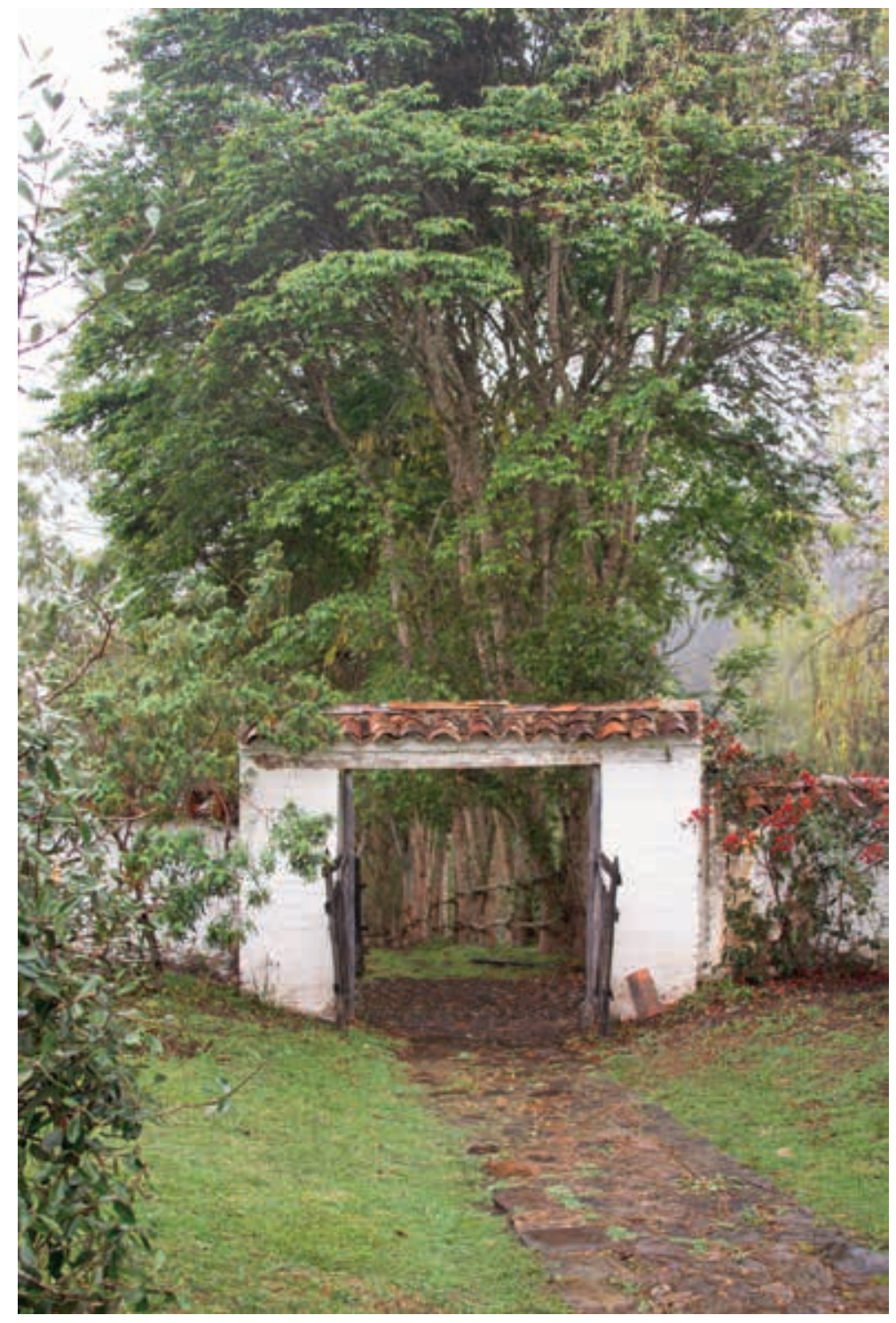


vicario, fray Tomás Ortiz, fundó en Santa Marta la primera casa e iglesia de la Orden en la actual Colombia y en 1529 fue electo como su primer obispo (Medina, 1992, nota I, p. 169). No obstante, Ortiz no fue consagrado porque tuvo que huir debido a la oposición de los conquistadores, que vieron con malos ojos la evangelización y defensa de los indígenas gairas, durcinos, tagangas, bondingas y bondas (Zamora, I980, t. I, libro II, p. I66).

Con el correr del tiempo llegaron otros grupos de misioneros. En I533, desembarcaron en Cartagena dos frailes y en 1534 se incorporó fray Tomás de Toro, su primer obispo y gran defensor de las poblaciones indígenas insulares de Carex, Mahates, Bahayre y Turbaco (Zamora, I980, t. I, libro II, p. I85). En I539, se agregó un tercer grupo con fray Jerónimo de Loayza a la cabeza como segundo obispo de Cartagena, quien llegó con una orden real que prohibía la esclavitud de los indios (Medina, I992, p. I72). Las incursiones en el altiplano cundiboyacense iniciaron tres años antes en abril de 1536 con fray Domingo de Las Casas, quien en 1537 implantó el cristianismo en la naciente población de Santa Fe (Zamora, I980, t. I, libro II, pp. I95-2I2). A la 


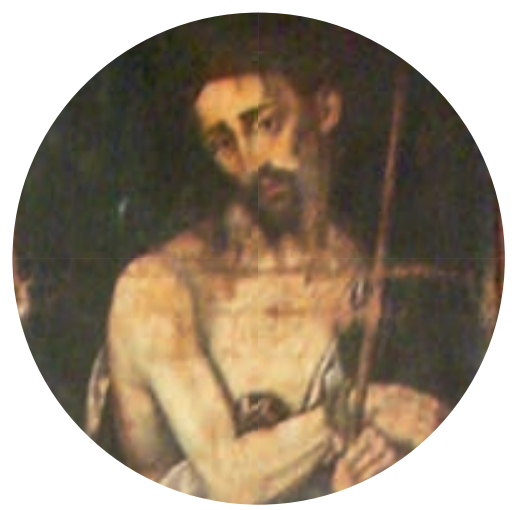

posterior provincia de Tunja también acudió fray Domingo de Las Casas, acompañando al conquistador Gonzalo Suárez Rendón, quien llegó exactamente al pueblo de indios llamado Uvaza, hoy en día vereda perteneciente al municipio de Moniquirá (Zamora, I980, t. I, libro II, pp. 213-220). En 1540, fray Pedro Durán, fray Juan de Montemayor y fray Juan de Torres iniciaron el trabajo sistemático de la evangelización de la población indígena (Rivadeneira, 2002, p. 45). 


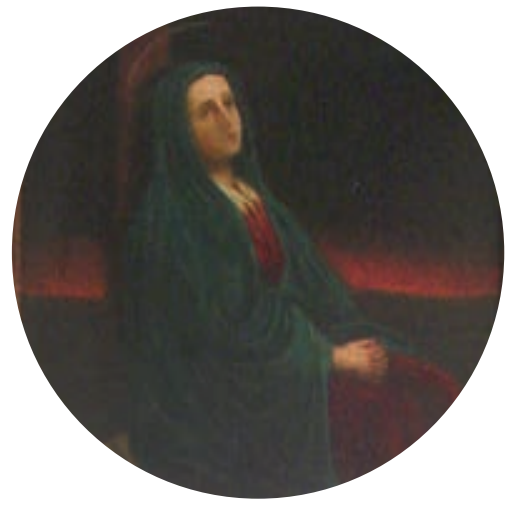

Pintura de la Virgen María

El convento de Santo Domingo de la ciudad de Tunja fue erigido el 4 de agosto de I55I por fray José Robles, vicario general de la Orden y fue él quien nombró como primer prior a fray Francisco López Camacho (Rivadeneira, 2002, p. 46) ${ }^{\mathrm{I}}$. En total seis frailes habitaban el nuevo convento y desde él

I El mandato de la fundación fue dado por el emperador Carlos V y aplicado desde Santa Fe el in de julio de 155I, Archivo Histórico Regional de Boyacá, orden real transcrita en Rivadeneira (2002, p. 46). 


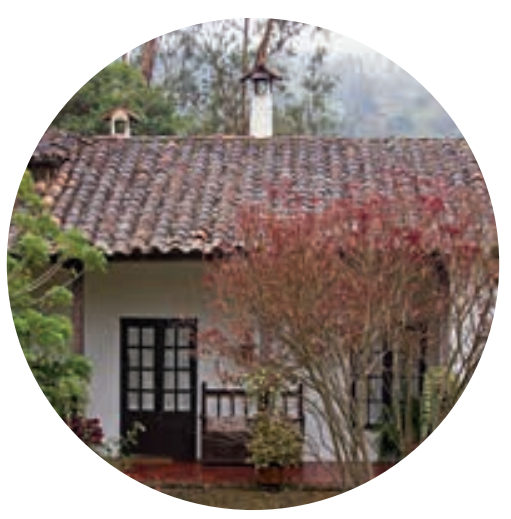

atendían la evangelización de 36 poblaciones, entre ellas las jurisdicciones de Turmequé y Tibaná, a las que perteneció la hacienda de Baza, motivo de esta publicación (Medina, I992, pp. I80, I83; Rivadeneira, 2002, p. 49). Finalmente, en cuanto a las barcadas de frailes procedentes de España destacan la de I562 con 30 religiosos —entre ellos fray Luis Bertrán y fray Luis Vero-y la de 1567 con 36, cantidad que en I571 sumó cien frailes con los que ya estaban y los que tomaron el 
hábito en los noviciados de los conventos de Santa Fe, Cartagena y Tunja (Medina, I992, pp. I82, I84).

La presencia de los dominicos en toda la Nueva Granada fue importante no solo por sus labores de evangelización y defensa de la población indígena, intereses primordiales de la comunidad, sino también por la introducción de instituciones educativas, porque entre otras en 1539, fray Jerónimo de Loayza estableció en Cartagena un colegio para que los hijos de caciques y principales estudiaran latín, artes y teología (Medina, I992, p.I72). Asimismo, en 1562 el convento de Tunja le pidió al rey de España su ayuda "para que podamos sustentar y dar de comer a estos colegiales a los que se ha comenzado enseñar a leer, escribir, contar, gramática y lengua española” (Ariza, I992, p. 632). En este colegio estudiaron los caciques de Turmequé, don Diego de Torres, y de Tibasosa, don Alonso de Silva (Rivadeneira, 2002, p. 7I). En Santa Fe de Bogotá, la Orden fundó en I580 la Universidad de Santo Tomás, el primer claustro neogranadino y en 1608 , el Colegio de Santo Tomás. 


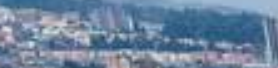

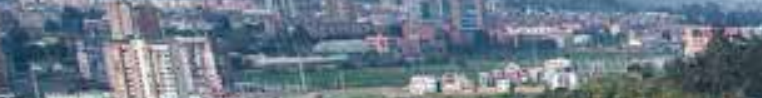

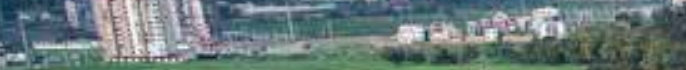

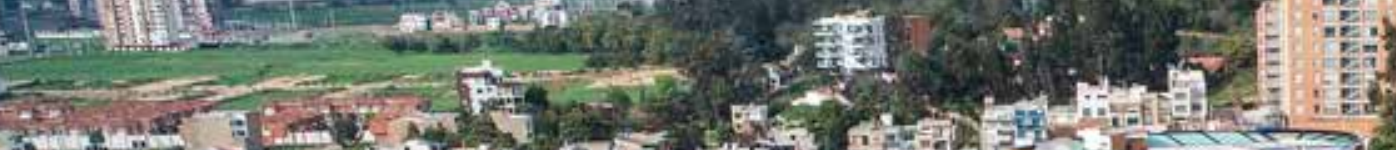

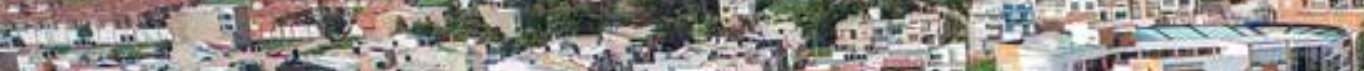

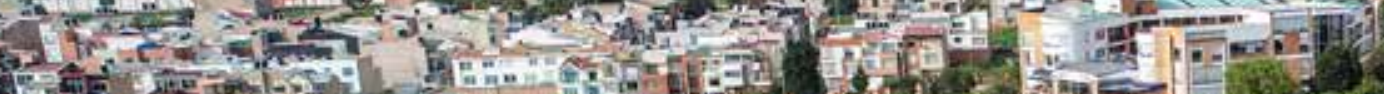
T.

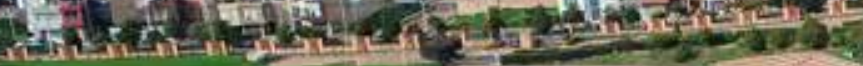

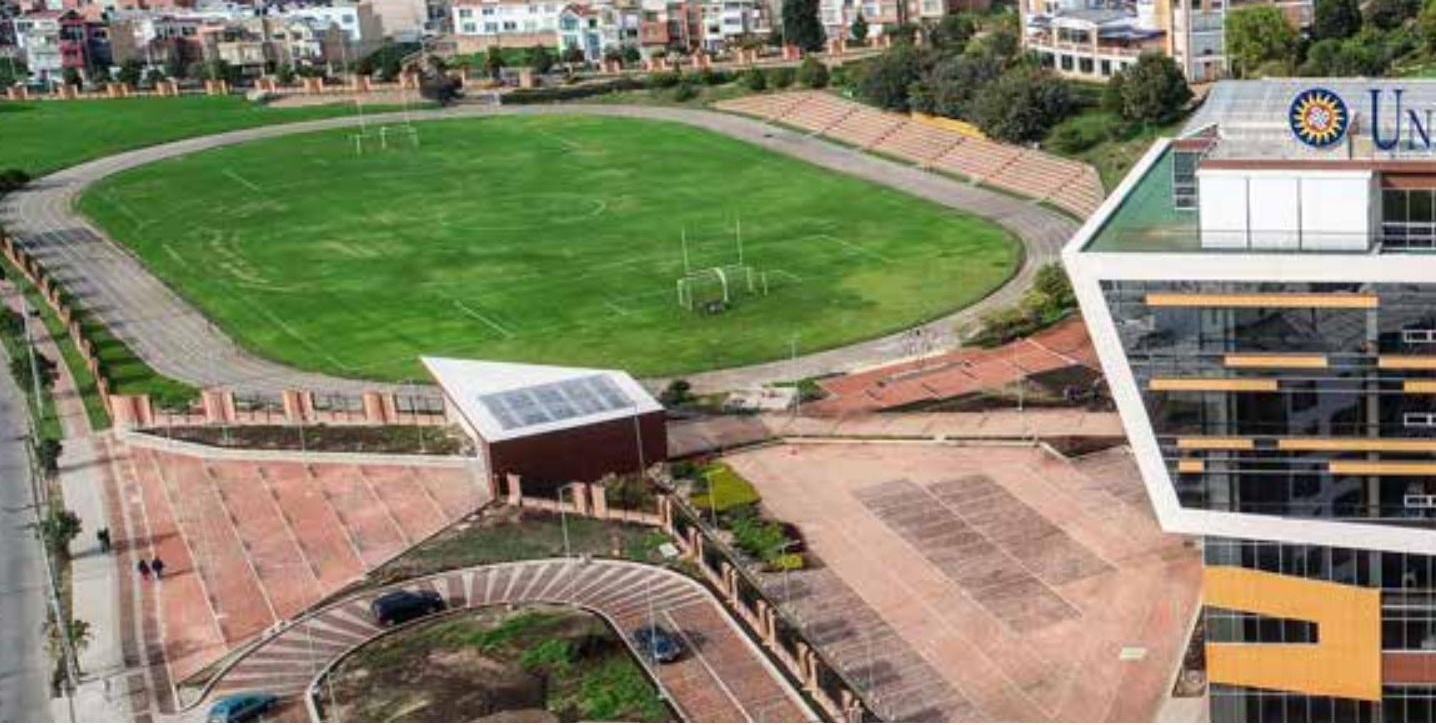

Universidad Santo Tomás,

Seccional Tunja 


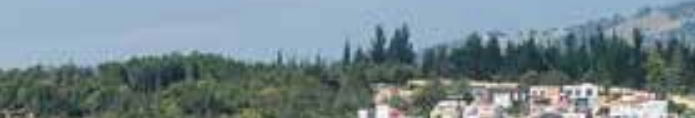

Se

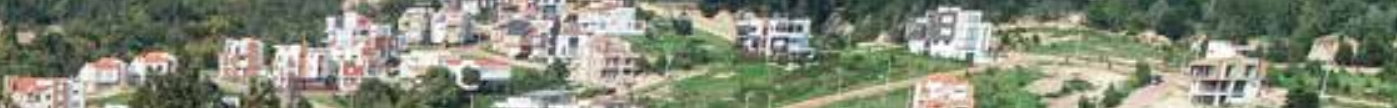

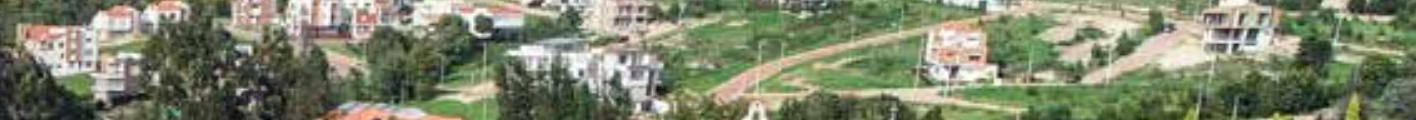

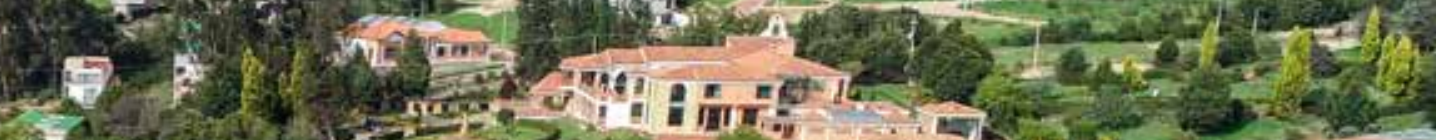

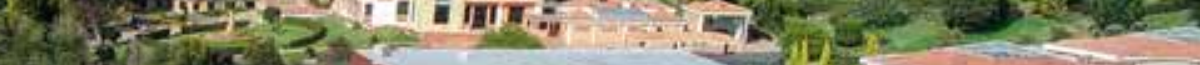

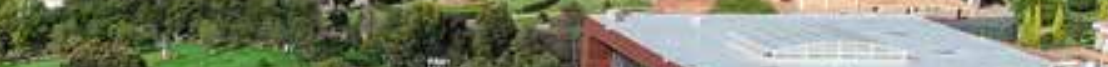
IVERSIDADSANTOIOMAS

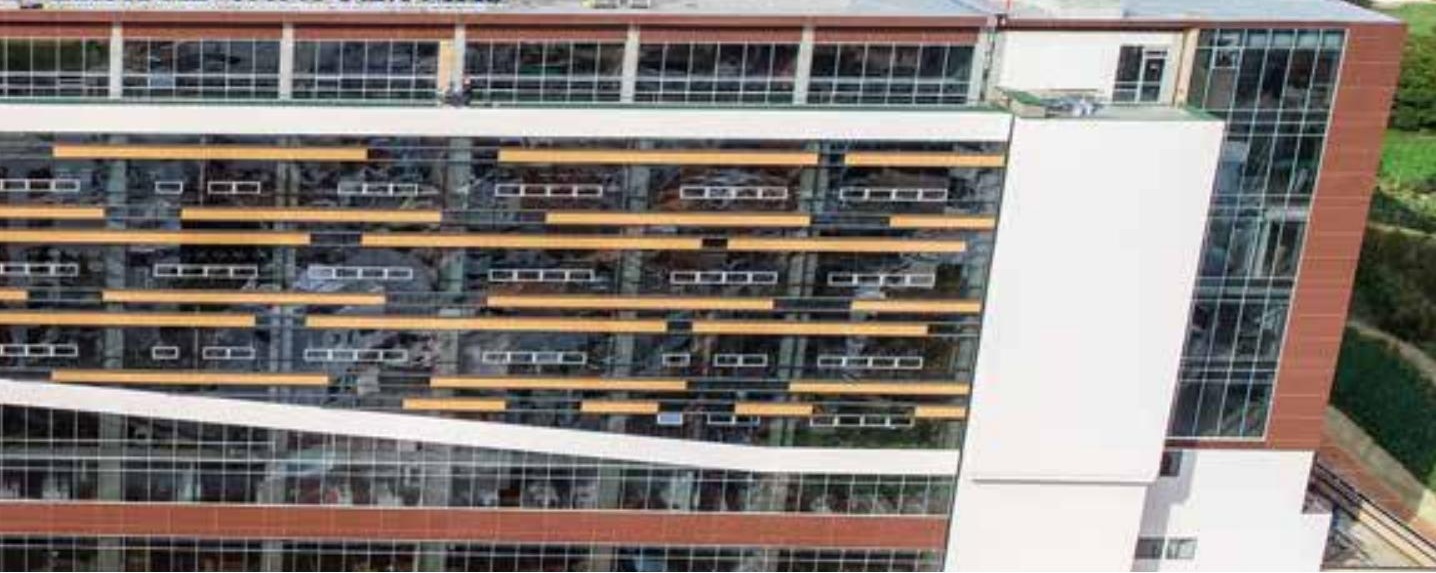


Hacienda Baza a comienzos

del siglo $\mathrm{xx}$

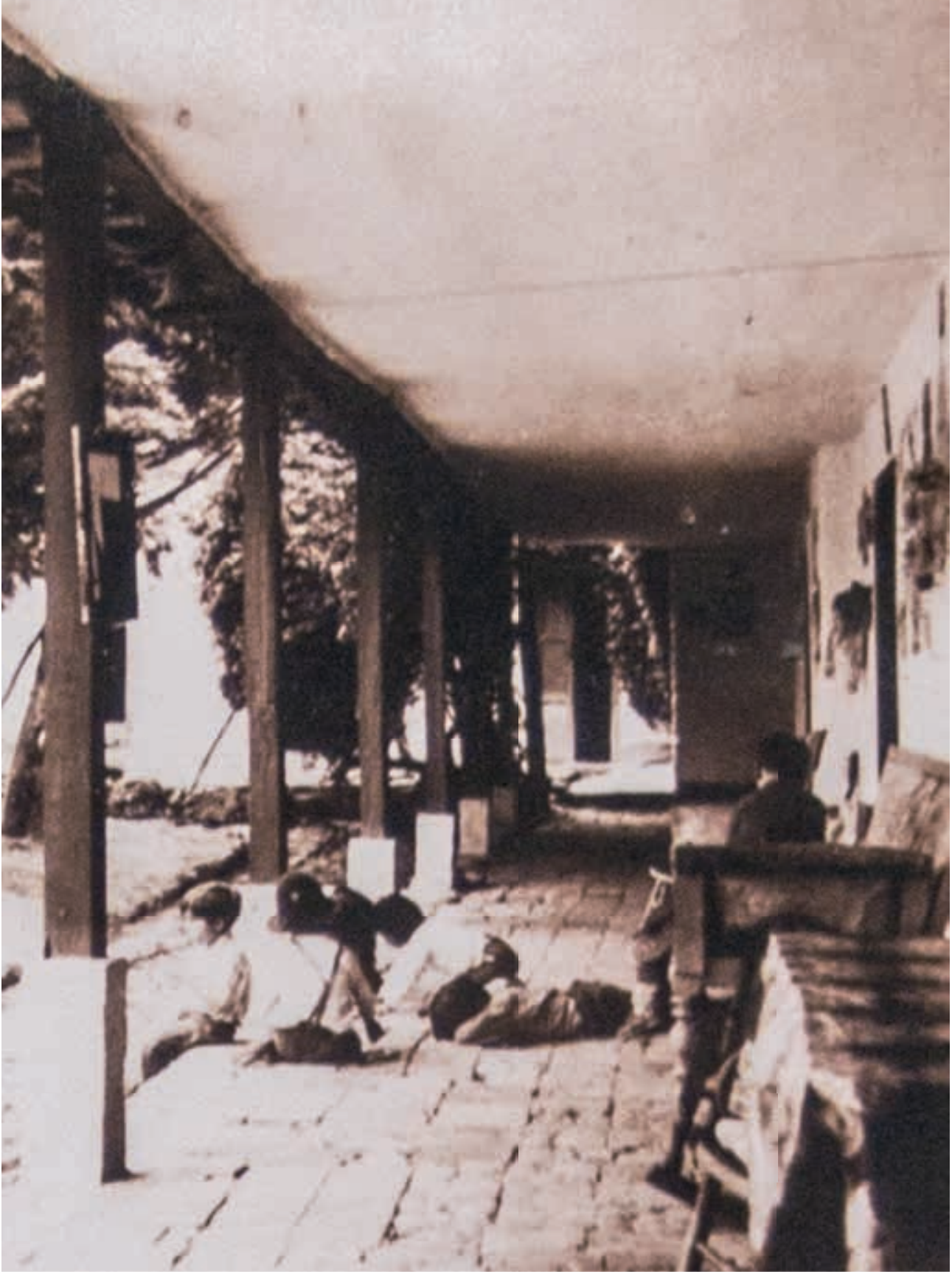

